\title{
Effective Teaching of Conservation of Mechanical Energy
}

\author{
Rankhumise Mmushetji Petrus \\ Raphoto Mosoalibisi \\ Joseph Ramathibela Maimane \\ Central University of Technology \\ Private BAG X20539, Bloemfontein, 9300 (RSA) \\ Email: mprankhumise@cut.ac.za
}

\section{Doi:10.5901/mjss.2014.v5n15p200}

\begin{abstract}
This study investigated learners' alternative conceptions of and conceptual difficulties of conservation of mechanical energy energy. The research sample consisted of thirty seven (37) learners enrolled at a South African high School situated in a rural village, in the Northwest Province. A pre-test/ post-test comparison group design was followed. Data analysis was carried out by the use of the average normalized gains. The questionnaire that served as pre- and post-test probed into learners' alternative conceptions and conceptual difficulties of mechanical energy. The effectiveness of the intervention was indicated by the amount of conceptual change accomplished that followed from a calculation of the normalised learning gain. The inquiry teaching was implemented through the $5 E$ instructional model. The teaching and learning experiences were designed using situations and experiences that were familiar to the learners and the success of the intervention to accomplish change was assessed and the normalized learning gains was found to be $72 \%$.
\end{abstract}

Keywords: Alternative conceptions, conceptual change, instructional model, normalized gains, mechanical energy

\section{Introduction}

The concepts of energy and conservation of energy are abstract, but more importantly, are fundamental and central in science as well as other subjects (e.g. technology, humanities, etc.) (Hewitt, 2002:p104; Boyes \& Stanisstreet, 1990:p51). This study focuses on learners' conceptual understanding of concepts relating to the principle of conservation of mechanical energy (in a closed system). Mechanical energy is the form of energy due to the relative position of interacting objects (potential energy) or due to their motion (kinetic energy) or both (Hewitt, 2002:pp106-107). The concept of mechanical energy is useful in describing motion (Cutnell \& Johnson, 2004:p159), i.e. in the study of kinematics.

More important than being able to state what energy, is to understand how it behaves, i.e. how it transforms (Hewitt, 2002:p111). Processes in nature can be understood when analysed in terms of energy changes. The study of various forms of energy and their transformations has led to one of the greatest generalizations in physics, namely the principle of conservation of energy. This principle can be formulated by the following: energy cannot be created or destroyed. It may be changed from one form into another, but the total amount of energy never changes.

Research studies show that even if learners receive formal instruction on concepts such as energy they still harbour, adhere to and hold firmly onto their alternative conceptions (Zain \& Sulaiman, 1998; Rankhumise \& Lemmer, 2008). This could have been brought about by the use of traditional teaching and learning strategies which are teacher centred and whereby the learner is the passive recipient of information and knowledge (Bybee, 2002). It is difficult for a teacher to change learners' alternative conceptions about any particular concept in formal teaching. For better understanding of scientifically correct concepts, it is essential that a combination of a variety of constructivist teaching and learning approaches are used (Trumper, 1991:p6; Trowbridge et al, 2000:224; Scott et al, 1991:p7).

The constructivist teaching-learning theory is at present the most frequently used theory associated with human learning worldwide (Trumper, 1991:p6). According to the constructivism principle, individual learners build their knowledge by making connections to existing knowledge (Redish, 2003). The principle of constructivism applied to the teaching and learning environment is embraced and contained in the OBE (Outcomes Based Education) principles that form the foundation for curriculum reform in South Africa (Department of Education, 2003). As a teaching and learning 
theory, constructivism can be implemented using strategies such as problem-solving and inquiry strategies (Gunter et al, 1991).

The problem attended to in this study is how to treat and handle learners' alternative conceptions relating to the principle of conservation of mechanical energy. The study investigates the effectiveness of an inquiry teaching-learning sequence aimed to remedy alternative conceptions that learners have relating to mechanical energy and the conservation thereof. The focus is on Grade 10 learners, because Grade 10 learners are introduced to the Further Education and Training (FET) level in which the concepts are formalized. Conceptual understandings of these concepts are vital before formalization (Lemmer \& Lemmer, 2005).

The teaching-learning sequence compiled and implemented in this study follows the design principles of progression and integration in the implementation of the OBE curriculum (Nieuwoudt \& Beckley, 2008:pp324-328). The progression principle enables learners to gradually develop more complex, deeper and broader knowledge, skills and understanding. The integration principle requires learners to apply their knowledge and skills in other contexts. In this study learners were required to integrate their classroom knowledge with everyday experiences.

Energy changes and the law of conservation of mechanical energy.

When energy is transformed from one form to another (in a closed system), no energy is lost in the process (Cutnell \& Johnson, 2004:p167). The observation that the total of all energies before and after a process is equal, leads to the principle of conservation of energy, namely that energy can neither be created nor destroyed, but can only be converted from one form to another.

Mechanical energy is the sum of the kinetic energy and gravitational potential energy of a system $\left(E_{\text {total }}=E_{k}+E_{p}\right)$. The principle of conservation of mechanical energy states shat the total mechanical energy in a closed system remains constant. A closed system is a system lacking dissipative forces, such as friction and/or air resistance, or a system in which such forces can be reasonably neglected (Kotz \& Treichel, 1996:259-260; Reynolds, 1974:pp5-10; Kelder et al, 2007:p45; Brookes et al, 2006:p40).

The pendulum is an example of the conservation of mechanical energy that is often used. A swinging pendulum has its greatest kinetic energy and lowest potential energy in the vertical position. In this position the speed of the pendulum is maximum and the height above the earth is the least. It has its lowest kinetic energy and greatest potential energy at the extremities of its swing. The speed at the extremities of its swing is minimum and the height is greatest. As the pendulum swings, energy is continuously changing back and forth between the two forms (kinetic and potential energy). Neglecting friction at the pivot and air resistance, the sum of kinetic and potential energy of the pendulum (mechanical energy) is constant.

The principle of conservation of mechanical energy offers a keen understanding of ways in which the physical universe operates (Cutnell \& Johnson, 2004:p161). For example, the mechanical energy of the Earth-moon system is nearly constant as it rhythmically interchanges between its kinetic and potential energy forms (Heyns et al, 2002:pp67-68; Kotz \& Treichel, 1996:pp257-260).

The inquiry teaching-learning strategy is not only confined within the limits of science teaching and learning. Inquiry is used in other areas of human learning such as social problems, politics, mathematics, literature, history and others. The inquiry teaching and learning strategy depicts the process through which human beings seek information and understanding through processes such as observations, experiments and experiences, which result in empirical evidence about the natural world. When learners study science using inquiry they employ many different skills (e.g. physical and intellectual skills).

Through inquiry the inquisitive nature of the learners is nurtured and they (learners) become motivated and interested in what they are doing. Once interested, the learners acquire cognitive skills and knowledge, and an increase in positive attitudes towards science learning is developed (Gunter et al, 1991:p43; Redish, 2003:pp156-161; Trowbridge et al, 2000:p175; Kask \& Rannikmae, 2006:p12; Bricker, 2005:p15, McBride et al, 2004:p434). The following skills are used and developed by using inquiry as a teaching-learning strategy:

Physical skills.

$>$ Gathering and setting up apparatus.

$>$ Making observations.

Taking measurements (recording data). Intellectual skills.

$>$ Analysing data.

> Making comparisons.

$>$ Evaluating results.

$>$ Preparing reports and communicating data to other learners or the teacher 


\section{Hypothesis}

Alternative conceptions and conceptual difficulties relating to the principle of conservation of mechanical energy that are found amongst Grade 10 learners can be remedied effectively by means of an inquiry-based teaching-learning sequence

\section{Methods}

\subsection{Research design}

The pre-experimental one-group pre-test-post-test research design was followed with a view to determining the effectiveness of the inquiry-based teaching learning sequence intervention.

\subsubsection{Research methodology.}

An action research methodology is used. Through action research opportunities are created where systematic reflections on classroom activities causing effective and efficient changes that are beneficial to both teaching and learning, can be made (Leedy \& Ormrod, 2001:p430; Feldman \& Minstrel, 2000:431). As explicitly defined by Leedy and Ormrod (2001:p432), action research is a way of taking a systematic, close and critical look at the way in which one teaches, with a view of changing it so that the classroom experiences become more meaningful for all those involved. Reflecting critically on what takes place in one's classroom is important to learners' learning as well as to advance the knowledge of the teaching and learning of science (Leedy \& Ormrod, 2001:p430; Feldman \& Minstrell, 2000:p431).

Action research is a contextualised form of research (it is done by the teacher on his or her own practice in his or her own classroom) and it is developmental in nature. I.e., a teacher is kept abreast and up to date with new developments in his or her discipline and profession, as is required by the Department of Education (Department of Education, 2003:p5; Feldman \& Minstrell, 2000:p432).

The purpose of choosing action research methodology for this study is to seek ways and means of improving teaching and learning as well as to have a better comprehension of the educational environment.

Implementation of action research.

The research method is divided into three stages namely action planning, action taking and the evaluating stage. The method (action research) of this study allows for modification of the intended intervention after analysing, evaluating and reflecting upon the results of the pre-test. The stages of the research design are outlined as follows:

$>$ Action planning - A pre-test questionnaire was prepared and administered to diagnose the alternative conceptions held by the learners. The alternative conceptions that have to be attended to in the intervention follow from the learners' responses.

$>$ Action taking (intervention) - Inquiry orientated lessons were designed and presented to learners in order to remedy alternative conceptions held or to build on already existing knowledge. Six lessons of forty-five minutes each were designed. The content of the lessons is contextualised, i.e., the activities are drawn up in such a way as to engage learners to use their daily experiences and observations while responding to the situations presented. Apart from participating in the lessons, the learners carried out a research project. To do the project, the learners were divided into six groups of about six learners per group. Each group was requested to record and report instances and situations where they had observed the application of mechanical energy transfer and its conservation from their immediate environment.

D Evaluating stage - The same questionnaire used in the pre-test was again used for the post-test. The statistical data of the pre- and post-tests is compared, analysed, interpreted and documented. Learning gains are calculated from these results. Conclusions and recommendations follow from the results.

\subsection{Participants and Setting}

An action research study was conducted with a class of thirty-seven Grade 10 learners (eighteen girls and nineteen boys). The learners are enrolled at one of high schools in the North West province in South Africa. The preferred as well as the first language of the learners is Setswana. English is used as a second language as well as the language of learning and teaching (LOLT). 


\subsection{Data Collection}

\subsubsection{Research instrument.}

A questionnaire was designed and used as both a pre- and post-test. The questionnaire developed for the study is based on learners' daily experiences and observations.

The biographical information.

In the biographical portion learners are requested to fill in the following information: Their names, gender, age and the date. The names of the learners and the dates of the administration of the questionnaire are used to determine the following:

$>$ Name: Names are used to determine the conceptual change and learning gains accomplished and whether constructive learning of individual members of the target group has taken place due to the intervention.

Part 1 of the questionnaire.

Part 1 of the questionnaire consists of six items. In each item a statement and a picture are given. The learners have to judge the correctness of the statements (called item statements). They have to choose what they think to be the most suitable response (Yes, No, Uncertain) and supply a reason to motivate their choices.

The items in this part of the questionnaire are diagnostic in nature. The aim is to find out about learners' alternative conceptions with regard to the principle of conservation of mechanical energy Item statements in Part 1 of the questionnaire refer to living and non-living objects as well as relative positions and actions of objects. These objects are contrasted with one another in order to find out the nature of the learners' alternative conceptions relating to the concept of energy.

Classification of items statements in Part 1 of the questionnaire.

The items in this part of the questionnaire are compared and contrasted with one another on the basis of their similarities, positions and or the key words used. The grouping or classification is done as follows:

For items 1.1 and 1.2, similarities rely on the relative positions of the objects and the word used (resting). However, the difference is the surface on which the ball is resting, for example:

$>$ Flat table (item 1.1).

$>$ Sloping surface (item 1.2).

Items 1.2 and 1.3 of the questionnaire are grouped because in both instances the object is placed on a sloping surface. However, the contrasting words were resting and speeding

Items 1.4 and 1.6 of the questionnaire introduce living objects. Although the objects are living they differ in their characteristics and their actions. For example:

$>A$ cat (an animal) is sitting (item 1.4).

$>A$ girl (human being) is stretching the strings of the bow (item 1.6).

Items 1.5 and 1.6 compare objects of similar nature and characteristics but in different situations. The catapult and the bow are used to launch stones and arrows respectively due to the elasticity of their strings. However, in the pictures they are depicted differently, for example:

$>$ Relaxed rubber bands (item 1.5).

$>$ Stretched bowstrings (item 1.6).

Items 1.1, 1.2, 1.3, and 1.5 all refer to non-living objects, while items 1.4 and 1.6both refer to living objects. This grouping and classification of the item statements in Part 1 of the questionnaire is done in order to diagnose the anthropomorphic and anthropocentric views of the learners

The content validity (the survey item should measure what it claims to measure) of the questionnaire was checked and judged by my study leader. After thorough checking and rechecking some suggestions were made to change some questions, questions statements, items, and item statements and the questionnaire was considered valid. An important factor that contributes to the validity is the composition of the items.

The reliability (reproducible results, not repeatable) of the questionnaire was determined by administering the same questionnaire to the target group a month later. The results of the pre-and post-tests were checked and evaluated to determine possible gains achieved (Redish, 2003:pp96-98). Matched items (e.g. item 1.1 and 2.4) were used to ensure reliability.

\subsubsection{Intervention}

Six teaching and learning experiences were designed in accordance with the National Curriculum Statement policy for 
grade 10 to 12 physical sciences (Department of Education, 2003:pp9-11). Attention was paid to the progression of the learners' knowledge. The teaching-learning experiences were contextualised, i.e., familiar and observable phenomena from the learners' environment were used

The main teaching-learning approach used was an inquiry strategy integrated with direct instruction and lecturebased models. The integrated teaching-learning approach is also highlighted in the learning outcomes of physical sciences in the NCS policy document (Department of Education, 2003:pp13-14).

Each teaching-learning experience consisted of three stages, namely:

$>$ Stage 1: Identification of two major forms of energy.

$>$ Stage 2: Discussion of energy changes that take place in the system and the principle of conservation of mechanical energy.

$>$ Stage 3: Application of the energy transformation concept and the principle of conservation of mechanical energy.

The first stage (lessons 1 and 2) was designed to enable learners to distinguish energy forms (potential and kinetic energy) from types of energy (like solar, chemical, radiation, etc.) and also to identify energy forms from types in a system (e.g. heat as the average kinetic energy of particles).

The concept of energy transformation and the principle of conservation of mechanical energy were introduced in the second stage (lessons 3 and 4). The purpose of these lessons was to create conflicting situations where learners would be able to recognize their limitations in explaining the concept of energy transformation and the principle of conservation of mechanical energy and would realize that their intuitions may be opposed to the scientific explanation. Learners were also expected to be able to quote and recognize the application of the principle of conservation of mechanical energy.

The final stage (lessons 5 and 6 ) was designed to help learners to be able to apply and recognize the application of energy transformation and the principle of conservation of mechanical energy in another context. In this stage learners were requested to do a case study in their environment and compile a report on situations where they had encountered or observed energy transformation and the principle of conservation of mechanical energy in application (for example, in the community a tractor with a malfunctioning self-starter is usually placed on a sloping surface in order to start). Others were asked to design (project) models where the principle could be applied (for example, some gates in the community can close automatically when opened; attaching a spring or rubber strand at one end of the gates does this).

Lesson plans and classroom activities.

Lesson 1 - definition of potential and kinetic energy.

In the developmental stage learners were requested to find definitions of the terms kinetic and potential energy from their textbooks. The presentation stage entailed active and interactive participation to identify energy forms in the system presented. Learners were always reminded to pay much attention to definitions given when identifying energy forms in the system. Teaching-learning materials used to facilitate the lesson were a soccer ball, a brick, and a shot put ball. During group work and reflection on the activities carried out, discussions and arguments between learners and learners and the teacher occurred freely. Teaching-learning activities designed were as follows:

Activity 1.1. Learners had to roll the balls and refer to the definitions of the terms to identify the energy form possessed by a rolling ball.

Activity 1.2. Learners had to raise and hold steady a shot put ball with an outstretched arm through different heights (knee level, waist height, shoulder height). In this activity learners had to identify the energy form possessed by the ball through these heights and then note and record the height where the ball becomes difficult to balance.

Activity 1.3. The masses of the three different objects (soccer ball, brick and shot put ball) were measured and recorded. The raising act was repeated for the three objects so that observations and comparisons could be made in order to arrive at conclusions.

Lesson 2 - a conceptualised approach.

A swing pendulum was designed as a teaching-learning aid. Learners were allowed to play with it for while. Activities that followed are outlined:

Activity 2.1. Pull and hold the pendulum at its maximum height. Identify the energy form it possesses at this height.

Activity 2.2. Let it return to its equilibrium position and hold it stationary at this position (minimum height).

Identify the energy form the pendulum has at this position.

Compare the two positions of the pendulum and indicate at which position it has more energy while at rest.

Activity 2.3. Let the pendulum swing.

Identify and note the energy forms that are displayed during its swings.

Activity 2.4. From your knowledge and experience name any mechanism or apparatus from your environment that 
has similar features to this pendulum.

Lesson 3 and 4 - the principle of conservation of energy.

In lessons 3 and 4 the principle of conservation of energy was introduced. In the introductory phase learners were provided with dictionaries to look up the words "law" and "conservation" and instructed to write down their meanings. The purpose was to make learners aware of the meanings of these words in everyday language use as opposed to their meaning in science. Activities, which followed to help learners, are reflected in the layout and design of lesson plans (see appendix B).

The lesson plans were designed according to NCS grade 10 to 12 physical sciences lesson planning requirements and standards (Department of Education, 2003:p17).

Lessons 5 and 6 - application stage.

A contextual project performed by groups of learners formed the application stage. In this stage learners were requested to conduct a case study from their immediate environment. In the case study the learners were requested to identify and recognize the application of the concept of energy and the principle of conservation of mechanical energy from their immediate environment.

Supporting evidence from their environment of learners' comprehension of the application of the concept of mechanical energy and its conservation was depicted by pictorial information brought forward as well as presentations, reports and discussions that followed.

\subsection{Data Analysis}

A statistical analysis is performed on the results of the pre- and post-tests. Normalized learning gains are calculated to determine the achievements of the inquiry-based teaching-learning sequence.

\section{Results and Discusiion of Results}

\subsection{Analysis of pre-test results.}

Part 1 of the questionnaire (diagnostic questions). Table 1 summarizes the pre-test results of Part 1 of the questionnaire. Learners' responses to the questionnaire items gave an indication of alternative conceptions held.

Table 1. Learners' responses to the diagnostic questions or item statements.

Responses (out of 37)

\begin{tabular}{|c|c|c|c|c|c|}
\hline ITEMS & TOTAL & YES & NO & UNCERTAIN & \% OF CORRECT RESPONSES \\
\hline 1.1 & 37 & 21 & 13 & 3 & 56 \\
\hline 1.2 & 37 & 17 & 16 & 4 & 46 \\
\hline 1.3 & 37 & 28 & 6 & 3 & 77 \\
\hline 1.4 & 37 & 26 & 6 & 5 & 70 \\
\hline 1.5 & 37 & 14 & 18 & 5 & 37 \\
\hline 1.6 & 37 & 31 & 6 & 0 & 83 \\
\hline
\end{tabular}

Learners' responses were analysed, classified and categorized according to the nature and origin of the alternative conception held.

The five randomly sampled learners gave the following reasons for their responses to the items:

Item 1.1. (A ball resting on a flat surface)

John: 'Wo, because the ball has lots of air inside. So ii has no energy."

Otshepeng: "Yes, if the table is taken out the ball is going to fall down."

Lilian: "Yes, because is big ball on top of the table"

Lephahamiso: "Yes, because it has energy to rest on top of the table."

Alinah: "Wo, if the ball rolls down it has energy and if it is standing or resting it has no

energy."

These responses were categorized and analysed as follows:

Association of energy with size: Lilian and John associated energy with size. Lilian 
responded by indicating that since the ball is big it has energy and John said a light ball has no energy.

Association of energy with motion: Otshepeng and Alinah referred to conditions that might cause the motion of the ball (it is going to "fall down" and it "rolls down"). This is a notion that can be used to improve the learners' understanding of the science concept of potential energy relative to a reference plane.

Everyday language use: Lephahamiso (it has energy to rest) and Alinah (if it is resting or standing it has no energy). This might mean that objects at rest have reserve energy or objects at rest are exhausted.

Item 1.2. (A ball resting on a sloping surface)

\begin{abstract}
John: "Yes, the slope is not like table. So the ball will want to move on top of the table"
Otshepeng: "No, the ball want to go down now it is resting:'

Lilian: "No, it does not go down, it does not energy to go down"

Lephahamiso: "No, because it has to move when it is on the slope and that ball is not moving."

Alinah: "Yes, because it is using energy to stop rolling down"
\end{abstract}

Association of energy with motion: John ("will want to move") and Otshepeng ("wants to go down"). These learners reasoned that given the nature of the slope, the ball will eventually roll down and when it is rolling, it is moving and it possesses energy.

Everyday language use: Lilian ("it does not go down"), Lephahamiso ("is not moving") and Alinah ("it is using energy to stop rolling down"). These arguments might mean that if the ball had energy, it would have moved because there is a slope. This might be associated with a person feeling tired and saying he does not have energy to move.

Item 1.3. (A rolling ball on a sloping surface).

John: "Yes, a ball is moving and it has moved by a slope, it has energy." Otshepeng: "Yes, because it falls down, it has energy"

Lilian: "Yes, when it goes down it gains energy because it is rolling and it has motion." Lephahamiso: "Yes, because when the ball moves it gain energy than when it is not." Alinah: "Yes, because it moving down, and it using energy to roll down"

Association of energy with motion: All learners were consistent in responding to this item. Since the ball was rolling, reference to motion was illustrated by the following key words picked from learners' responses to this item:

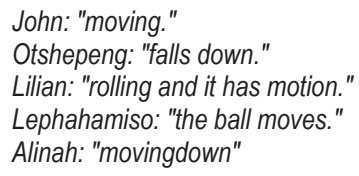

Item 1.4. (A sitting cat)

\begin{abstract}
John: "Yes, because if someone scars it, it will run away immediately. I think when it is sitting it has lot of energy" Otshepeng: "Yes, because this cat has energy. If there is no energy the cat will not liver

Lilian: "No, I think this cat is too hungry, it seems that this cat does not have energy:'

Lephahamiso: "Uncertain, because I am not sure whether the cat have energy or does not have energy."

Alinah: "Yes, because you can see it look like it will jump something or do something, is looking like it can kill something."
\end{abstract}

Association of energy with living objects: John (if scared, it will run away because at that position it has energy), Otshepeng ("If there is no energy the cat will not live.") and Alinah ("it looks like it will jump"). These answers imply that the cat is a living being and it has energy whether it is at rest or not. The association of energy with living beings or with what they do is anthropomorphic in nature.

Association of energy with motion and from everyday language use: Lilian ("I think the cat is hungry"). This might mean that when a person says she/he is hungry, he or she does not have energy to do anything. Alinah ("it looks like it will jump"). The word jump indicates movement and more emphasis is put on the activity of the cat.

Lephahamiso was uncertain and her uncertainty could be attributed to the sitting position of the cat. I.e., she knows or might understand that the cat is living and has energy, but because of its sitting position, the cat was tired and hence it does not have energy.

Item.1.6. (The girl with bow strings stretched). 
John: "Yes, the girl is giving the strings energy"

Otshepeng: "Yes, because this girl help stretched to get energy."

Lilian: "Yes, it is having because of the girl. The girl gives it energy by pulling it"

Lephahamiso: "Yes, the girl is pulling the strings to give them energy."

Alinah: "Yes, it having energy of the girl"

Energy as a human centred activity: The catapult is isolated from the system as illustrated by the learners' responses. Energy is only considered as human activity. This is illustrated by the responses of the learners for item 1.6.

These sampled responses that were correct for items 1.4, 1.3 and 1.6 show that many learners associated energy with living beings and motion. As reflected from their responses, the strings of the bow in item 1.6, even if they were held stretched, were not considered to possess energy. The anthropomorphic and anthropocentric views of energy are revealed by these responses (see paragraph 5.3.3).

Item 1.5 was poorly responded to as compared to the other items already analysed and discussed $(37 \%$ of the responses recorded was correct. The poor responses for this question can be attributed to the anthropomorphic and anthropocentric views of the learners. These views are also revealed from the reasons given by learners when responding to the statement of this item.

Item 1.5. (Relaxed rubber bands of the catapult).

\author{
John: "Yes, because it has energy to push the stone to hit someone or something, but if there is no one pulling it, there \\ will be no energy" \\ Otshepeng: "No, because they have no energy" \\ Lilian: 'Wo, because these rubber bands are resting" \\ Lephahamiso: "Yes, because those rubber bands give the stone energy." \\ Alinah: 'Wo, because there is no one pulling the catapult."
}

The human centred energy view is also displayed in this item (it has similar features to item 1.6). The following ideas were picked up from learners' responses: John: "if there is no one pulling it, there will be no energy. Alinah: "there is no one pulling the catapult"

For Otshepeng ("they have no energy") and Lilian ("are resting") the responses indicated that since the rubber bands are not stretched, the rubber bands are at rest and therefore they do not possess energy. Or, because there is no human element in the system, the rubber bands on their own cannot possess energy.

Lephahamiso ("give the stone energy") was the only one to indicate that the rubber bands have energy because they can launch stones. A limited and unclear comprehension of the concept of potential energy was displayed by Lephahamiso's response.

John and Alinah's responses ("there is no pulling") imply an understanding that work has to be done to give the catapult energy. None of the learners considered energy that objects possess on the microscopic level due to vibration or motion of atomic or molecular particles, or forces between the particles.

These results also confirm the findings of Driver and Warrington (1985:p171), Boyes and Stanisstreet (1990:p51), Kabapinar et al, (2004:p636), Wesi, (2003:p248), Osborne and Freyberg (1995:p6-7) and Watt (1995:pp214-216)

In synthesizing the results for part 1 of the pre-test the following factors were identified:

$>$ Language proficiency of the learners was lacking and inadequate. This is highlighted in paragraph 1.4.

$>$ Learners' pre-knowledge about the concept of energy and energy forms in the system was confused and blurred. This is illustrated by their inconsistent responses to questionnaire items.

$>$ Learners' alternative conceptions of energy tend to be anthropocentric and anthropomorphic in nature.

$>$ Kinetic energy is better understood than potential energy

Although limited, learners display ideas about energy that can be linked onto, broadened and refined in order to learn the scientific conception of energy, as is proposed by the constructivist theory

Classroom observations during the intervention.

While doing the inquiry activities of the intervention the learners responded to oral questions asked by the teacher as well as written questions on prepared work sheets.

Results for lesson 1.

From the activities carried out during the teaching-learning sequences designed to remedy learners' alternative conceptions about the concept of energy and the law of conservation of energy, the following were common responses from learners to guiding questions asked by the teacher: 
Activity 1.1. Two balls (shot put and soccer ball) are rolled along a flat horizontal surface.

Guiding questions:

$>$ Do the rolling balls possess energy?

From the list of scientific definitions of terms, identify the energy form possessed by the rolling balls.

Common responses:

$>$ The balls have energy because they are moving.

$>$ The balls have energy of motion.

$>$ The balls have kinetic energy.

Activity 1.2. The raising act. Learners had to raise and hold steady a shot put ball at different levels (e.g. knee level, hip level and shoulder height).

Guiding questions:

$>$ What energy form does the ball possess through these heights?

$>$ At which height do you find it difficult to balance the shot put ball?

$>$ Compare the height through which the ball was raised to the work done to raise it and draw conclusions from your observations.

Common responses:

$>$ The ball possesses stored energy.

$>$ The energy is due to position.

$>$ Potential energy is seen as stored energy.

$>$ It is easy to lift the ball to knee level.

$>$ At shoulder height the ball seems to be heavier.

$>$ At shoulder height the ball is more difficult to balance as compared to knee level.

$>$ There is more potential energy at shoulder height.

$>$ The higher you raise the ball the more work is done.

Activity 1.3. The raising act as in activity 1.2 was repeated using two balls (soccer and shot put).

Guiding questions:

$>$ Which ball is the lighter of the two?

$>$ Which ball is easy to raise through the different heights mentioned? Motivate your answer.

$>$ Which ball will hurt you most if it fell on your toe? Motivate.

Common responses:

$>$ The soccer ball is lighter than the other materials.

$>$ The soccer ball is easy to be raised through different heights because it is the lightest.

$>$ The shot put ball is difficult to be raised because it is heavier than the other materials.

$>$ The shot put ball will hurt most if it falls on your toe.

$>$ The shot put ball will break your toe because it has more mass.

$>$ The shot put ball has more stored energy and it will break your toe.

Analysis of the responses:

Analysis of the responses for activity 1.1 gives an indication that energy due to motion is always recognized. A reason could be that energy is associated with motion in everyday life as well as in science.

For activity 1.2 the concept of the gain in potential energy was gradually developed because learners were able to recognize that the ball was difficult to be raised to shoulder height as compared to knee level. For activity 1.3 learners were able to tell that an object with more mass possesses more stored energy. It is interesting to note the responses that refer to the consequences of having a high potential energy (e.g. "break your toe" and "hurt most"). This idea corresponds with the scientific concept of energy as the ability to do work. A conceptual understanding of the concept of work and the dependence of potential energy to the height and mass of an object, paves the way to formalization of the concepts.

Results for lesson 2.

The following responses were recorded during the activities:

Activity 2.1. The swinging pendulum.

Guiding questions:

$>$ The pendulum is at rest or equilibrium. What energy form does it possess?

$>$ The pendulum is pulled and held stationary at its maximum position. What energy form does it possess at this position?

Common responses: 
If it is not moving it has potential energy.

$>$ It is high up there, therefore it has potential energy.

Activity 2.2. The swinging pendulum continued.

Guiding questions:

> Measure and compare the heights at which the pendulum is held stationary (at equilibrium and when pulled to its maximum position).

$>$ Identify the energy form possessed by the pendulum at these heights.

$>$ At which height does the pendulum possess more energy?

Common responses:

$>$ It is held at rest so it has stored energy.

$>$ If it is not moving it has energy.

At the highest position there is more stored energy.

$>$ There is more energy at the top.

Activity 2.3. The swinging pendulum (energy changes within the system).

Guiding questions:

$>$ The pendulum is allowed to swing. Identify the energy forms displayed by the swinging pendulum.

Common responses:

When it is high up there it has potential energy.

$>$ However, when it swings it has energy of motion.

$>$ Swinging is shaking and moving so it possesses kinetic energy.

Dhen it starts to swing, potential energy is converted to energy of motion

\subsection{Post-test results.}

Post-test Part 1 (diagnostic questions or item statements).

These results serve as a yardstick to diagnose and determine whether scientifically correct conceptions were constructed after the intervention phase. The responses of the same sampled learners for the post-test results of Part 1 of the questionnaire show that learners were able to recognize, identify and name energy forms in the system. The concept of energy as a property of both living and non-living matter was also established.

Table 2 provides the results of the post-test for Part 1 of the questionnaire after the intervention was conducted.

Table 2: Learners' responses to the diagnostic questions or item statements.

Responses (out of 37)

\begin{tabular}{|c|c|c|c|c|c|}
\hline Item & Total & rYes & No & Uncertain & \% Of Correct responses \\
\hline 1.1 & 37 & 34 & 2 & 1 & 91 \\
\hline 1.2 & 37 & 34 & 3 & 0 & 91 \\
\hline 1.3 & 37 & 33 & 2 & 0 & 89 \\
\hline 1.4 & 37 & 34 & 3 & 0 & 91 \\
\hline 1.5 & 37 & 30 & 6 & 1 & 81 \\
\hline 1.6 & 37 & 36 & 0 & 1 & 97 \\
\hline
\end{tabular}

\section{Statistical Analysis of the Results}

Tables 3 present the statistical analysis of the results by comparing pre- and post-test results of both Part I of the questionnaire though calculation of the average normalized learning gain). The average learning gain achieved for each question or item statement was worked out using the following formula:

Gain = actual average gain - maximum possible gain (Redish, 2003:p43)

To illustrate the calculations, the normalized gain for item 1.1 of the questionnaire was determined as follows:

Actual average gain $=$ post-test $\%$ - pre-test $\% 91 \%-56 \%=35 \%$.

Maximum possible gain $=100 \%$ - pre-test $\%$

$100 \%-56 \%=44 \%$.

The average normalized gain = actual average gain - maximum possible gain

$35 \% \div 44 \%=08$. 
Expressed as percentage, the normalized gain is $80 \%$ for item 1.1 of the questionnaire. This means that, learners had a learning gain of 0.8 or $80 \%$.

Part 1 of the questionnaire

Table 3 shows the calculated average normalized gains for each question or item statement as well as the total average normalized gain for Part 1 of the questionnaire.

Table 3: Calculated normalized gain for Part 1 of the questionnaire

\begin{tabular}{|c|c|c|c|c|}
\hline Item & Actual Gain Post-Pre-Test $\%$ & $\begin{array}{c}\text { Possible Gain 100\%-Pre- } \\
\text { Test } \%\end{array}$ & $\begin{array}{c}\text { Normalized Gain Actual Gain \% } \\
\text { Possible Gaen } \%\end{array}$ & $\begin{array}{c}\text { Expressed As \% Normalized } \\
\text { Gain * } 100 \%\end{array}$ \\
\hline 1.1 & $91 \%-56 \%=35 \%$ & $100 \%-56 \%=44 \%$ & $35 \% \div 44 \%=0.8$ & 80 \\
\hline 1.2 & $91 \%-46 \%=45 \%$ & $100 \%-46 \%=54 \%$ & $45 \% \div 54 \%=0.83$ & 83 \\
\hline 1.3 & $89 \%-77 \%=12 \%$ & $100 \%-77 \%=23 \%$ & $12 \% \div 23 \%=0.52$ & 52 \\
\hline 1.4 & $91 \%-70 \%=21 \%$ & $100 \%-70 \%=30 \%$ & $21 \% \div 30 \%=0.7$ & 70 \\
\hline 1.5 & $81 \%-37 \%=44 \%$ & $100 \%-37 \%=63 \%$ & $44 \% \div 63 \%=0.7$ & 70 \\
\hline 1.6 & $97 \%-83 \%=14 \%$ & $100 \%-83 \%=17 \%$ & $14 \% \div 17 \%=0.82$ & 82 \\
\hline \multicolumn{2}{|r|}{ Total Average } & $4.37 \div 6=0.72$ & $72 \%$ \\
\hline
\end{tabular}

The total average normalized gain gives the summary or the average normalized gain for Part 1 of the questionnaire. The last column of the table gives the gains expressed in percentage form. The total average normalized gain for Part 1 is $72 \%$.

The normalized gain for item 1.3 of Part 1 of the questionnaire is significantly lower than the normalized gains of the other items (item 1.1, 1.2, 1.4, 1.5 and 1.6). It can be deduced from the results of the pre- and post-test that the learners performed well for this item. The reason might be that during the pre-test learners overemphasized the word speeding and associated it with energy possessed by a rolling ball. In the post-test, learners were able to indicate the kind of energy illustrated by the rolling ball.

The research findings are categorized and analysed according to two stages namely, pre-test and post-test results. The analysis of the pre-test results of the empirical study conducted confirms that the learners used for the study had alternative conceptions regarding the concepts relating to the conservation of mechanical energy similar to those found in physics education research. Their alternative conceptions correspond with those given in the literature (e.g. Watt, 1983:p213; Wesi, 2003:p260), for example, association of energy with living things and motion, energy expenditure, energy as a fuel, etc. This observation might mean or could be generalized as a common trend of alternative conceptions found in or held by secondary school learners in South Africa regarding concepts relating to energy and conservation of mechanical energy.

The analysis of the post-test results shows an improvement in the learners' conceptual understanding of concepts relating to the conservation of mechanical energy. These concepts include the science concepts of energy, kinetic energy and potential energy. The analysed learners' responses also show that learners were able to indicate and note energy transformations taking place in the system. The learners' progress was recorded. For example, energy was recognized and regarded as the property of matter (both living and non-living) by most of the learners. Learners also noted relative positions of objects as an indication of potential energy.

In the study conducted, the progress of grade 10 learners (target population) was evident in the analysis of the post-test responses of learners after the intervention was conducted. The progression in thinking for the learners regarding the concepts relating to the principle of conservation of energy could be attributed to the advancement and development of cognitive skills and knowledge. The abstract thinking and knowledge of the learners became more advanced, refined and developed.

\section{Conclusion and Recommendations}

In conclusion, the constructivist teaching-learning approach puts more emphasis on the learning process rather than on the teaching process. The emphasis is towards learner-centred learning, i.e., an approach to education in which the teacher's role is less that of an expert and more that of a skilled facilitator. Also, content that is derived from and taught within a context that is familiar and accessible to learners as well as the use of contemporary constructivist teaching and learning approaches (e.g. inquiry teaching-learning strategies as used in the research study) could play a pivotal role in 
strengthening a learner-centred learning environment favourable for both the learner and the teacher.

It is recommended that, when teaching the principle of conservation of mechanical energy, the first activity the teacher has to do is to diagnose learners' alternative conceptions of related concepts (e.g. potential energy and energy transformations). The importance of the pre-test is to diagnose the existing knowledge of the learners before introducing a new topic. The reason for administering the pre-test is because the core knowledge, energy, is not specified clearly in the GET band also provides guidelines and directives on how to plan and design effective teaching and learning experiences for the learners. In this way the constructivist principle stated by the Ausubel and Piagetian elements of teaching and learning are adhered to. This constructivist approach to teaching and learning broadens and builds on learners' pre-knowledge and progressively refines it towards the scientific conceptions.

\section{References}

Boyes, E \& Stanisstreet, M.(1990). Misunderstandings of "law " and " conservation": A study of pupils' meanings of these terms. School science review, 72(258): 51(Sep).

Bricker, P. (2005). Inquiry is essential to science learning. Connect, synergy learning. March-April.

Brookes, D.; Gibbon, D. \& Patrick, M. (2006). OBE for FET Physical sciences. Grade 12 Learner's book. Nasou Via Africa. South Africa. Bybee, R.W. (2002). Learning science and science of learning: science educators' essay collection. Arlington, Virginia: NSTA Press.

Cutnell, DJ. \& Johnson, W. K. (2004). Physics. John Wiley and Sons, Inc.

Department Of Education. (2003). National Curriculum statement grade 10-12: Physical sciences. South Africa.

Dilley, L., HalL, M.; Ndwandwe, M. \& Tsipa, A. (2005). Physical sciences. Teachers' guide grade 10. Maskew Miller. Longman Ltd.

Driver, R \& Warrington, L (1985). Students' use of the principle of energy conservation in problem situations. Physics Education.

Feldman, A. \& Minsterll, J. (2000). Action research as a research methodology for the study of the teaching and learning science. In A.E. Kelley, and R. Lesh (Eds). Handbook of research design in mathematics and science education. Mahwah. NJ. Earlbaum.

Gunter, A. M; EsteS, T. H. \& Schawb, J. (1991). Instruction. A model approach. Allyn and Bacon.

Hewitt, P.G.(2002). Conceptual physics. 9th edition. New York: Addison Wesley.

Heyns, G.F.; de Villiers, G.; Jordan, A. S.; Naidoo, L. R. \& Fowler, W. G. (2002). New physical science Grade 12. OBE for FET. Learners Book. Nasou. South Africa.

Kabapinar, F.; Leach, J. \& Scott, P. (2004). The design and evaluation of teaching -learning sequence addressing the solubility concept with Turkish Secondary Students. International journal of science education, 26 (5)) 635-652

Kask, K \& Rannikmae. (2006). Journal of Baltic science education, No.I (9).

Kelder, K.; Govender, D. \& Govender, J. (2007). Physical sciences. Grade 12 Learner's book. Cambridge university press. South Africa.

Kotz, J.C. \& Treichel, P. (Jr). (1996). Chemistry and Chemical reactivity. (3rd edition). Harcourt Brace College Publishers.

Leedy, P.D. \& Ormrod, J.E. (2001). Practical research: Planning and design.(7th Ed). Upper Saddle River, NJ: Merrill/ Prentice Hall.

Lemmer, M. \& Lemmer, T.N. (2005). Contextualisation as a didactical approach to physics education. (In: Grayson, D.J. (Ed) What Physics should we teach? Proceedings of the International Physics Education Conference, Durban, 5-8 July 2004.) p 212 - 218.

McbridE, W. J.; Bhatti, I. M; Hannan, A M. \& Feinberg, M. (2004). Using an inquiry approach to teach science to secondary school science teachers. Physics education, 39(5).

Niewoudt, H.D. \& Beckley, W. (2008). Participative teaching. (In: Jacobs, M. Vakalisa, N. \& Gawe, N. Teaching-learning dynamics: A

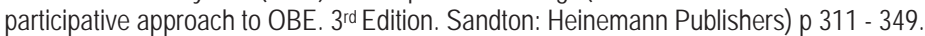

Osborne, J. \& Dillon, J. (2007).Research on learning in informal context: Advancing the field. International journal of science education, (29) 12: 1441-1445.

OSBORNE, R. \& FREYBERG, P. (1995). Learning science. The implication of children's science. Heinemann Education. New Zealand.

Rankhumise, M.P. \& Lemmer, M. (2008). Effective teaching of energy in grade 10 mechanics: A case study. Accepted for publication in the Proceedings of the $16^{\text {th }}$ annual conference of SAARMSTE, 14-18 January, Maseru, Lesotho.

Redish, E. F. (2003). Teaching physics with the physics suite. John Wiley and Sons INC. University of Maryland. USA.

REYNOLDS, W. C. (1974). Energy form nature to man. McGraw Hill Book Company.

Scott, P. H.; Asoko, H. M. \& Driver, R. H. (1991). Teaching for conceptual change. A review of strategies. http://www.phvsics.ohiostate.edu/ jossem/ICPE/C5.htm.. Date of access. 05 June 2006.

Trowbridge, L. W.; Bybee, R. W. \& Powell, J.C. (2000). Teaching Secondary School Science. Strategies for developing scientific literacy. (7th edition). Merrill, An imprint of Prentice Hall. Upper Saddle River. NJ. Columbus, Ohio.USA.

Trumper, R.O. (1991). Being Constructive. An alternative approach to the teaching of energy concept. Part two. International journal of Science Education, 13: 1-10.

Wesi, P.R. (2003). Conceptual difficulties associated with the energy concept. Thesis submitted in the school of science, mathematics and technology education. Potchefstroom University. Potchefstroom. RSA.

Watt, M.D. (1983). Some alternative views of energy. Physics education, 18: 213-216.

Zain, A.D.MD. \& SULAIMAN, F. (1998). Physics students' conceptions of energy and technological development in energy. Renewable energy, 14: 415-419. 